\title{
A Clinical Study to Assess the Efficacy of Anterior Trans- articular C1-C2 Screw Fixation for Stabilization of Atlanto- Axial Instability
}

\author{
Varun kumar Agarwal ${ }^{1}$, Naveen Mahaur ${ }^{2}$, Praveen Garg ${ }^{3}$, R.K. Narula ${ }^{4}$ \\ ${ }^{1}$ Associate Professor, Department of Orthopaedics, RMCH, Bareilly, U.P., ${ }^{2}$ Resident, Department of \\ Orthopaedics, RMCH, Bareilly, U.P., ${ }^{3}$ Associate Professor, Department of Orthopaedics, RMCH, Bareilly, U.P., \\ ${ }^{4}$ Professor, Department of Orthopaedics, RMCH, Bareilly, U.P.
}

\begin{abstract}
Introduction: The upper cervical spine includes the atlas (C1) and Axis (C2). The anatomy of upper two vertebrae is unique from each other. Atlanto-axial articulation is the most unique, mobile segment of spine, which largely depends on ligamentous supports based on integrity of odontoid for its stability. Historically, atlanto-axial subluxation was treated by reduction and fusion of C1-C2 joint. However, High riding vertebral artery precludes the placement of posterior trans-articular screw, which is liable to injury during screw placement. Socomputed tomography scans can be used to evaluate the risk of "high riding" vertebral artery during the management of atlanto-axial subluxation. Hence, anterior trans-articular screw fixation technique avoids the course of high riding vertebral artery.
\end{abstract}

Material and Method: Nine patients underwent NCCT cervical spine with 3-D reconstruction and clinical evaluation of pain was done by recording the VAS score done pre operatively and after surgery.

Results: All surgical cohorts underwent anterior C1-C2 fixation with an average follow up for 24 months. All patients were assessed as per fixed protocol of our local hospital guidelines of orthopaedics department. Pain score was clinically evaluated by VAS score before and after surgery yielding $90 \%$ excellent result.

Conclusion: Anterior Trans-articular C1-C2 screw fixation isa minimally invasive technique with less blood loss, shorter skins car and faster post-operative recovery. It is an appropriate technique for stabilization of Atlanto-Axial instabilities.

Keywords: Anterior trans-articular C1-C2 screw fixation, high riding vertebral artery, visual analog scale.

\section{Introduction}

The anatomy of upper two vertebrae, atlas (C1) and axis $(\mathrm{C} 2)$ is unique from each other. Atlanto-axial articulation is the most mobile segment in spine and largely depends on ligamentous supports due to integrity

\section{Corresponding Author:}

\section{Dr. Naveen Mahaur}

Resident, Department of Orthopaedics, RMCH, Bareilly, U.P.

e-mail: drnaveenmahaur7@gmail.com

Mobile No.: 8126409300 of odontoid for its stability ${ }^{1}$. The criteria for instability in literature is defined as atlanto-dens interval (ADI) greater than $3 \mathrm{~mm}$ in adults and $5 \mathrm{~mm}$ in children, respectively ${ }^{2}$. Common causes of Atlanto-axial instability include trauma, tumour, rheumatoid arthritis, infection and congenital anomalies ${ }^{2}$. Historically,clinically or radiological significant Atlanto-axial subluxation is traditionally treated by reduction and fusion of $\mathrm{C} 1-\mathrm{C} 2$ joint by wiring method which includes Gallie's fusion with Halifax clamps ${ }^{3}$, Brooks method along with Jenkins fusion ${ }^{4}$, Sonntag posterior C1-C2 technique ${ }^{5}$ and Magerl technique ${ }^{6}$ which comprises of posterior trans-articular screw fixation along with bone graft. Currently, Goel's and Harm's technique ${ }^{7}$ has been popular amongst spine 
surgeons. . "High riding" vertebral artery precludes the placement of posterior trans-articular screw and which is liable to injury during screw placement. So, during the management of atlanto-axial instability, computed tomography scans can be used to evaluate the risk of "high riding" vertebral artery. Percutaneous atlanto-axial anterior trans-articular screw fixation combined with mini-open posterior C1-C2 fusion has been described to overcome this hurdle, and avoid injuring vertebral $\operatorname{artery}^{3}$.

Smith-Robinson approach ${ }^{8}$ of anterior cervical spine has been associated with satisfactory clinical outcome, reduced infection and complication rate. Anterior approach to $\mathrm{C} 1-\mathrm{C} 2$ permits prevention of occipital nerve exposure and potential for post-operative $\mathrm{C} 2$ neuralgia. $^{2}$ This technique has various advantages among different method of atlanto-axial instability management. This technique is considerably less traumatic and utilizesan essential space rather than going through muscles, thereby lowering the rate of infection and gives more cosmetically justifiable scar. This approach also reduces the risk of vertebral artery injury because the starting point is far away from the vertebral artery foramen. Additionally, the occipital condyles restrict potential migration of a Kirschner wire or positioning of a long screw that would otherwise risk injuring adjoining nervous structures.
With the standard anterior approach, percutaneous anterior trans-articular screw fixation can be achieved with a minimal skin incision ${ }^{13}$. The benefit includes that it is minimally invasive with lowerbloodloss, shorterskinscar and faster post-operativerecovery.

\section{Material and Method}

A total of nine patients from Nov. 2018 to Oct. 2019, (6 men and 3 women) were selected for atlantoaxial,anterior trans-articular screw fixation was done in our department. The mean age was 34.4 (range 1056) years.All patients having atlanto-axial instability were investigated with Magnetic resonance imaging (MRI) and non-contrast computed tomography (NCCT) scanning with angiography. Out of nine patients, eight patients came to our hospital with traumatic injury of C1-C2 junction (90\%) and one patient suffered from $\mathrm{C} 1-$ $\mathrm{C} 2$ degenerative osteoarthritis.Patients were assessed as per standard protocol of our hospital in our orthopaedic department. The standard radiograph included anteroposterior and lateral view along with open mouth view of the cervical spine, (Figure $1 \mathrm{a}, 1 \mathrm{~b}$ and 1c). Further imaging included NCCT Cervical spine with 3-D Reconstruction along with MRI Cervical spine with screening of wholespine (Figure 1d).Clinically, VAS score was recorded pre-operatively and after surgery.
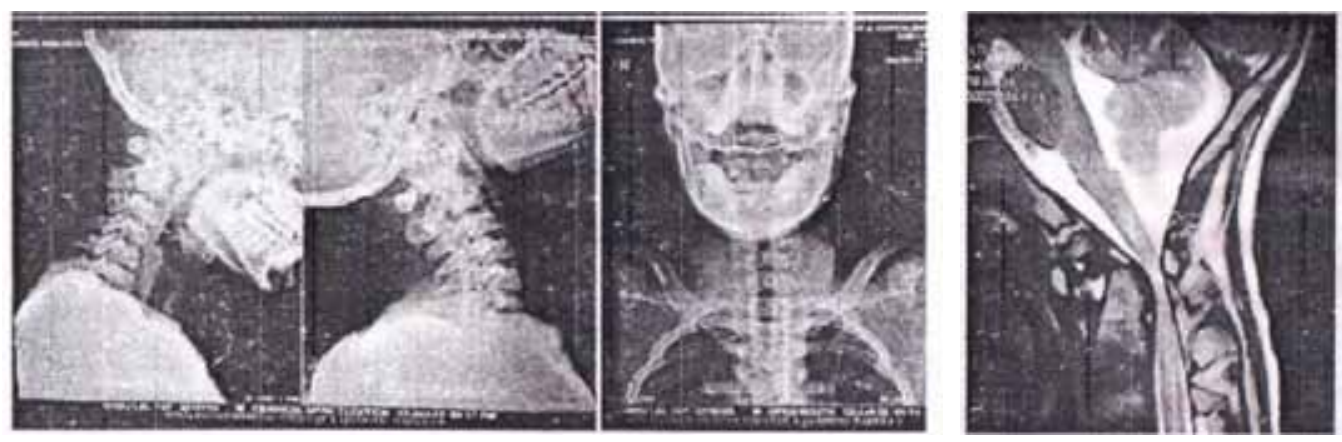

Fig. 1 showing preoperative X-rays of Cervical spine AP, Lateral and open mouth view with 1 MRI image

Surgical Technique ${ }^{11}$ : All patients were operated under general anaesthesia. The head was pulled in the straight line with Crutchfield skull tongs to attain anatomic reduction of odontoid fracture. High-quality intra-operative fluoroscopic visualization of the upper cervical spine was ensured before draping the patient sterile. A clear visualization of $\mathrm{C} 1$ lateral masses and $\mathrm{C} 1-\mathrm{C} 2$ joints is a prerequisite. It is preferable to verify opening of the mouth, in order to use simultaneously, two C-arms one for latero-lateral and another for an
Antero-posterior open- mouth view, to limit the operative time and trajectory inaccuracy. A classic C4-C5 left anterior retropharyngeal approach was carried out after having fluoroscopic latero-lateral and AP open mouth images. The prevertebral dissection must be lengthened proximally to anterior tubercle of $\mathrm{C} 1$. On anterior arch of $\mathrm{C} 1$, a radiolucent retractor was placed.Joint capsule was then incised, and the articular surfaces of C1-C2 joint were carved with the help of long curved curettes. 
The technique described by Lu et $\mathrm{al}^{9}$. and first applied by Reindl et $\mathrm{al}^{10}$ recognized the entry point of k-wire on the undersurface of the overhanging lip of the lateral mass of $\mathrm{C} 2,4$ to $5 \mathrm{~mm}$ lateral to base of the odontoid process, with $25^{0}$ of lateral inclination. Two $3.5 \mathrm{~mm}$ self-cutting cannulated partially threaded cortical screws were preceded from anterior-to-posterior and medialto-lateral along threaded Kirschner wires under image intensifier. It is advisable to avoid further advancement of K-wires beyond the anatomic limits, already detailed. A drainis left in place after final radiological check; the platysma muscle and skin are sutured in standard manner. All patients were able to consume meals and mobilized actively on first postoperative day with Philadelphia collarin situ upto 30 days.
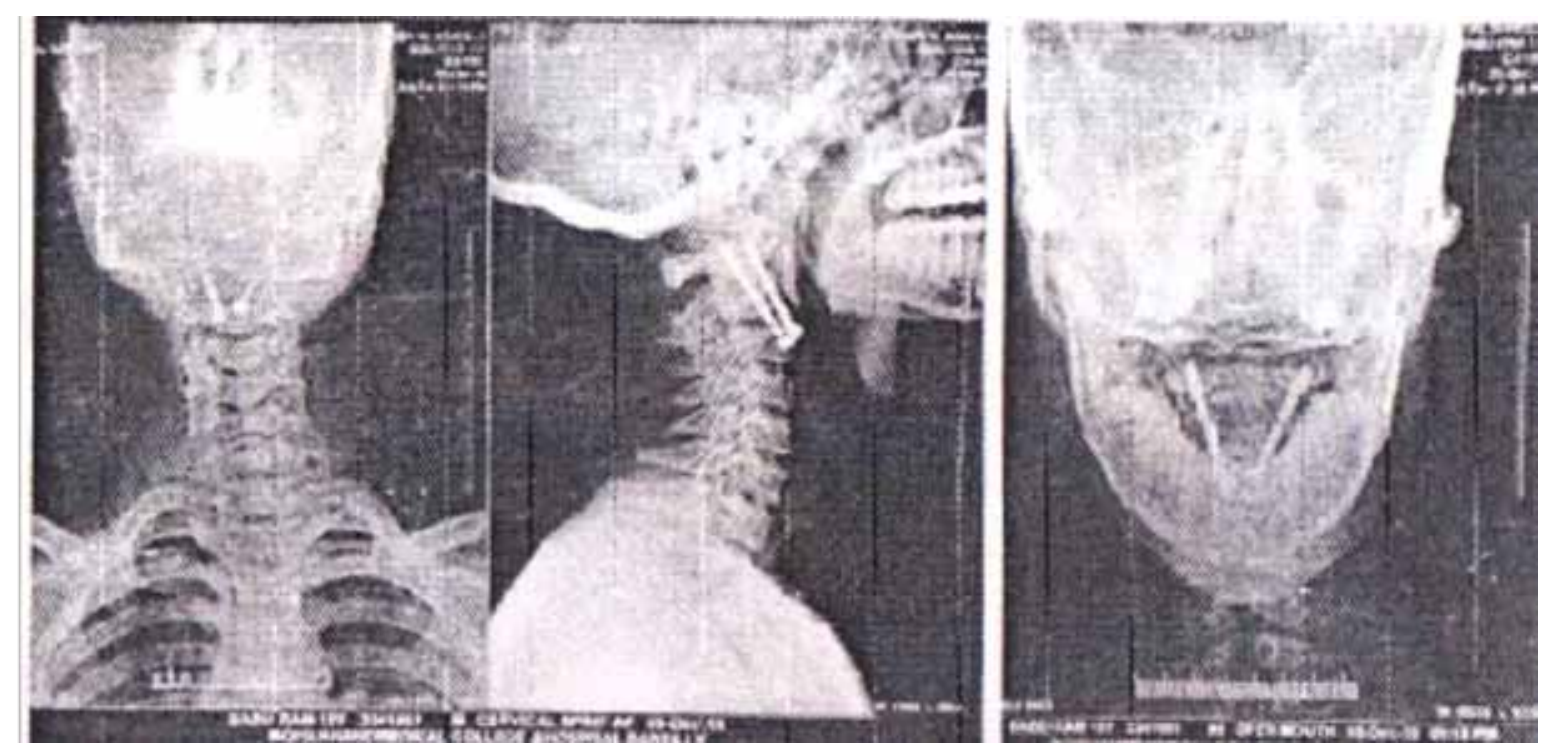

Fig. 2 showing postoperative X-rays AP, Lateral and open mouth view after ATS

\section{Result}

All patients underwent surgery within 3 days of hospital admission. The mean operative time was 76.7 (range 53-136) minutes and none of the patient had blood loss more than $30 \mathrm{ml}$. Complications such as nerve injury, spinal cord injury, oesophageal injury, soft tissue injury were not reported in any of patients. All of the 9 patients were followed up (Table 2) for an average of 30 months (range from 24 to 48 months). No loosening or breakage of screw was seen. The pain and functional outcomes were recorded. For all the 9 patients VAS ${ }^{11}$ of neck pain (Table 1) was enhanced significantly from $4.93+/-1.20$ at pre-operation to $1.18+/-0.64$ at 3 months after operation $(p=0.000)$ and maintained at the final follow up, with $1.02+/-0.36(p=0.420)$. With the use of a
Philadelphia collar,early mobilization could be possible in all patients. The mean time until mobilization was 2.4 (range 1.5-4 days) including the interval between surgery and drain removal. All patients should wear Philadelphia collar for 30 days. Eventually, there was no infection, implant failure, or morbidity after the procedure in any of the cases.

Table 1. VAS score done pre and postoperatively with $p$ value

\begin{tabular}{|l|c|c|}
\hline & VAS score & p value \\
\hline Pre-operation & $4.93+/-1.20$ & \\
\hline Post-operation at 3 months & $1.18+/-0.64$ & 0.000 \\
\hline Final follow up & $1.02+/-0.36$ & 0.420 \\
\hline
\end{tabular}


Table 2. Surgical and postoperative clinical data of 9 patients treated with ATS

\begin{tabular}{|c|c|c|c|c|c|c|c|}
\hline Patient & Treatment & $\begin{array}{c}\text { Operative } \\
\text { time (min) }\end{array}$ & $\begin{array}{l}\text { Blood loss } \\
\quad(\mathrm{ml})\end{array}$ & $\begin{array}{l}\text { Neurological } \\
\text { impairment: } \\
\text { ASIA Preop }\end{array}$ & $\begin{array}{l}\text { Neurological } \\
\text { impairment: ASIA post } \\
\text { op at follow up }\end{array}$ & $\begin{array}{l}\text { Follow up } \\
\text { (month) }\end{array}$ & $\begin{array}{c}\text { Bone fusion } \\
\text { (wk) }\end{array}$ \\
\hline 1 & ATS & 60 & 30 & E & E & 6 & 18 \\
\hline 2 & ATS & 65 & 40 & $\mathrm{E}$ & $\mathrm{E}$ & 12 & 14 \\
\hline 3 & ATS & 70 & 60 & $\mathrm{C}$ & $\mathrm{E}$ & 29 & 12 \\
\hline 4 & ATS & 85 & 20 & $\mathrm{D}$ & $\mathrm{E}$ & 38 & 18 \\
\hline 5 & ATS & 95 & 30 & $\mathrm{E}$ & $\mathrm{C}$ & 60 & 20 \\
\hline 6 & ATS & 105 & 50 & $\mathrm{C}$ & $\mathrm{E}$ & 48 & 21 \\
\hline 7 & ATS & 70 & 60 & $\mathrm{E}$ & $\mathrm{E}$ & 15 & 10 \\
\hline 8 & ATS & 75 & 70 & B & $\mathrm{C}$ & 30 & 12 \\
\hline 9 & ATS & 80 & 45 & $\mathrm{D}$ & $\mathrm{E}$ & 22 & 14 \\
\hline
\end{tabular}

\section{Discussion}

Atlanto-axial instability has been treated by variety of method such as wiring techniques ${ }^{3}$, posterior trans-articular screw fixation with bone graft ${ }^{6}$, Goel-Harm's technique ${ }^{7}$. In 2003, Reindl et al ${ }^{10}$ conducted a study on cadavers using the classic Smith-Robinson retropharyngeal approach ${ }^{8}$ to perform anterior trans-articular C1-C2 fixation in traumatic aetiology. Anterior trans-articular C1-C2 fixation has clear superiority over posterior approaches. Anterior trans-articular C1-C2 screw fixation superiority minimizes vertebral artery injury and spinal cord injury. Anterior screw fixation was relatively secure and safer for anatomic variations of the vertebral artery. The supine position with head in slight extension, via anterior approach for trans-articular screwfixation, minimizes the risk of spinal cord compression and is especially favourable inpoly-trauma patients. Surgical anatomy of anterior Trans-articular screw fixation decreases the risk of trauma to spinal cord and $\mathrm{C} 2$ roots and decreases bleeding from venous plexus around vertebral artery ${ }^{1}$. The anterior $\mathrm{C} 1-\mathrm{C} 2$ Trans-articular screw fixation had comparable biomechanical properties to the posterior C1-C2 Trans-articular screw fixation according to human cadaveric biomechanical studies ${ }^{3}$. Anterior retropharyngeal approach wasmore acceptable because it was minimally encroaching and associated with negligible muscle trauma, minimal or no blood loss, and faster recovery ${ }^{2}$.

The potential complications of Atlanto-axial anterior Trans-articular screw fixation are connected to the trajectory of K-wire and screws in order to avoid damage to vertebral artery, dural sac and spinal cord. Atlanto-axial anterior Trans-articular screw fixation is not feasible in fixed rotatory atlanto-axial subluxation and certain conditions where spinal cord decompression is deemed necessary. Cranio-cervical malformations, basilar invagination and platybasia are relative contraindications of atlanto-axial anterior trans-articular screw fixation.

\section{Conclusion}

In conclusion, anterior trans-articular C1-C2 screw fixation is minimally encroaching, achievable and secure technique. The authors established the anatomical suitability of anterior trans-articular screw fixation as an acceptable technique for stabilization of atlanto-axial instability. The above described approach has various advantages in comparison to posterior approach. In cases of failed percutaneous odontoid screw fixation, percutaneous anterior C1-C2 fixation is a finepossible salvage technique and it is minimally encroaching ${ }^{2}$.

Ethical Clearance: Taken from institutional ethical committee of Rohilkh and medical college and hospital.

Source of Funding: Self

Conflict of Interest: Nil 


\section{Reference}

1. B D Chaurasia. Human Anatomy Regional and Applied Dissection and Clinical Volume 3 Head and Neck, Brain, $5^{\text {th }}$ Ed. New Delhi, CBS Publisher and Distributor; 2010.

2. Carrier CS, Sama AA, Girardi FP, Lebl DR. Anterior transarticular screw fixation for atlantoaxial arthrodesis: A report of two cases. Journal of Craniovertebral Junction and Spine. $2013 \mathrm{Jul} ; 4(2): 85$.

3. Dossani RH, Shaughnessy J, Kalakoti P, Nanda A. William Edward Gallie (1882-1959): father of the Gallie wiring technique for atlantoaxial arthrodesis. Journal of neurosurgery. 2017 May 26;128(3):93841.

4. Schicho A, Riepl C, Scola A. Brook's Wiring for Treatment of an Atlanto-Axial Dislocation and Odontoid Fracture in a Child. MOJ Clin Med Case Rep. 2015;3(3):00067.

5. Tran M, Wadhwa R, Ziewacz J, Mummaneni P, Chou D. Comparison between C1-2 Fixation with and without Supplemental Posterior Wiring. Evidence-based spine-care journal. 2014 Apr;5(1):12.

6. Magerl F, Seemann PS Stable posterior fusion of the Atlas and Axis by Trans-articular screw fixation. In: Kehr P, Weidner A (eds) Cervical spine I. Springer, Wien, 1987;322-327

7. Du YQ, Li T, Ma C, Qiao GY, Yin YH, Yu XG. Biomechanical evaluation of two alternative techniques to the Goel-Harms technique for atlantoaxial fixation: $\mathrm{C} 1$ lateral mass- $\mathrm{C} 2$ bicortical translaminar screw fixation and $\mathrm{C} 1$ lateral mass$\mathrm{C} 2 / 3$ transarticular screw fixation. Journal of Neurosurgery: Spine. 2020 Jan 17;32(5):682-8.

8. McAfee PC, Bohlman HH, Riley LH Jr, Robinson RA, Southwick WO, Nachlas NE. The anterior retropharyngeal approach to the upper part of the cervical spine. J Bone Joint Surg Am. 1987 Dec;69(9):1371-83.

9. Lu J, Ebraheim NA, Yang H, Heck BE, Yeasting RA. Anatomic considerations of Anterior Transarticular screw fixation for Atlanto-Axial instability. Spine (Phila Pa 1976) 1998;23:1229-35.

10. Reindl R, Sen M, Aebi M. Anterior instrumentation for traumatic C1-C2 instability. Spine. 2003;28: E329-E333.

11. Wu AM, Jin HM, Lin ZK, Chi YL, Wang XY. Percutaneous anterior $\mathrm{C} 1 / 2$ transarticular screw fixation: salvage of failed percutaneous odontoid screw fixation for odontoid fracture. Journal of orthopaedic surgery and research. 2017 Dec 1;12(1):141.

12. Li WL Chi YL, Xu HZ, Wang XY, Lin Y, Huang QS, et al. Percutaneous anterior Trans-articular screw fixation for Atlanto-Axial instabilities: J Bone Joint Surg Br 2010;92:945-9

13. Koller H, Kammermeier V, Ulbricht D, Assuncao A, Karolus S, Van Berg B, et al. Anterior retropharyngeal fixation $\mathrm{C} 1-\mathrm{C} 2$ for stabilization of Atlanto-Axial instabilities: study of feasibility, technical description and preliminary results. Eur Spine J 2006;15:1326-38 